\title{
Notes on Biston betularia industrial melanism in the Copșa Mică area
}

\author{
Sergiu TöRÖK \& László RÁKOSY
}

\begin{abstract}
Summary: The aim of our study is to evaluate the abundance of melanic forms of Biston betularia in the year 2012 from the Copșa Mică area. This locality is well known for the high pollution level caused by the synergic action of $\mathrm{SO}_{2}$, soot black and heavy metals. The two industrial units, which were the pollution sources were closed and the now the pollution level decreased. We captured moths monthly from all eleven sampling points situated in woodland habitats. Results show that the proportion of black form carbonaria has drastically declined since 1987-1988. In the vicinity of the pollution source carbonaria form was $96 \%$ in 1987-1988 and in 2012 the proportion is only $60 \%$. Overall the abundance of carbonaria also decreases with the increase of distance from the pollution source. In these sites carbonaria has only less than half it was recorded at the end of the 80 's.
\end{abstract}

Key words: Industrial melanism, Biston betularia, atmospheric pollution, Copșa Mică, renaturation

\section{Introduction}

The Copșa Mică area was one of the most polluted sites in the world (Ianculescu et al. 2009), the nonferrous metallurgy factory SC SOMETRA SA based here emitting extremely high concentrations of atmospheric emissions (Lăcătușu and Lăcătușu 2010). The negative effects of this unit were amplified by another industrial unit, the carbon black smoke factory SC CARBOSIM SA which emitted other types of pollutants. The most damaging to vegetation was the sulphur compounds emitted by the metallurgy factory, the black smoke from the second industrial unit only enhanced the effects of the sulphur compounds (Ianculescu et al. 2009). Soil, litter, vegetation and fauna were all affected by these pollutants. Based on the level of pollutants found in litter and vegetation, Barbu (2006) and Ianculescu et al. (2009) recognized three levels of degradation due to pollution, the forest stands closest to the pollution source being the most affected. On insect populations, one effect was the overall decrease of diversity and another was the occurrence of melanic forms (Sanda et al. 1976, Rákosy and Rákosy 1997). Biston betularia is world renowned for its three forms: carbonaria, insularia and typica. In Britain, the carbonaria form was strongly associated with high levels of atmospheric coal pollution (Kettlewell 1961, Clarke and Sheppard 1966, Less 1981). A similar association was recorded in the Copșa Mică area in the year 1987-1988; the proportions of carbonaria form in close proximity to
Copşa Mică reached 92.6 up to $100 \%$ revealing an extremely polluted site (Rákosy and Rákosy 1997). In the two other cities (Mediaș and Blaj) the percentages of this form decreased, and the proportion of the insularia form increased (Rákosy and Rákosy 1997). The SC CARBOSIM SA was closed the 1993 and in 2009 the main pollution source SC SOMETRA SA suspended its activity (Szanto et al. 2011). The aim of this research is to highlight the changes that have occurred in $B$. betularia melanic form frequencies, revealing the health of forest stands from Copşa Mică area in the year 2012 .

\section{Material and methods}

Eleven sampling sites were selected closely matching the sampling localities used in the first study from 1987-1988. The collection points were set in forest habitats. Sampling was done during April and September 2012 using two $8 \mathrm{~W}$ black light traps powered by $12 \mathrm{~V}$ batteries for each site. In order to increase trap efficiency warm nights, with clear sky and without full moon were chosen. The sampling was done twice a month.

\section{Results and Discussions}

The results of our research recorded significant frequency differences in melanic forms between the two periods 1987 and 2012 (Tabel 1). In the intensely polluted area the carbonaria form was absolutly 


\begin{tabular}{ccccc}
\hline \multicolumn{1}{c}{ Sampling sites } & Year & \multicolumn{3}{c}{ No. of individuals } \\
\cline { 3 - 5 } & & typica & carbonaria & insularia \\
\hline \multirow{2}{*}{ Intensly polluted sites } & 1987 & 0 & 17 & 0 \\
\multirow{3}{*}{ Medium polluted sites } & 2012 & 1 & 12 & 7 \\
\multirow{2}{*}{ Unpolluted sites } & 1987 & 7 & 28 & 15 \\
& 2012 & 0 & 18 & 6 \\
& 1987 & 16 & 9 & 3 \\
\hline
\end{tabular}

dominant in 1987, reaching 100\%, whereas in 2012 the percentage of the black carbonaria form had declined drastically $(60 \%)$, the intermediates insularia is $35 \%$ and we encounter even the black and white typica form (Fig. 1).

The decline of the carbonaria form is also found in the medium polluted forest stands, where the insularia form was the most common in 2012 (Fig. 2). Percentages of the melanic forms in medium and unpolluted sites are very similar, in the past and now. Comparing the overall situation between 1987 and 2012, the insularia form is dominating now; percentages of $75 \%$ and $80 \%$ were recorded in the medium and unpolluted sites. In the medium damaged stands only half the percentage of carbonaria can be found in 2012 and in the unpolluted sites the percentage of carbonaria decreased by $33 \%$ (Fig. 3). The typica form specimens are absent in 2012 in the medium polluted sites; this might be an effect of natural selection and also low trapping success. It should be mentioned that the insularia form specimens are morphologically diverse; we can encounter individuals that resemble with typica form and specimens with the carbonaria form. The decline of carbonaria was encountered in Britain and North America where measures to prevent the atmospheric pollution had been taken (Clarke and Sheppard 1966, Grant et al. 1998).

The pollution levels from Copșa Mică area had been gradually decreasing after 2009 when the nonferrous plant SOMETRA was closed; this led to changes to the vegetation. The occurrence of melanic forms in the Copșa Mică area can be explained according to some authors to gene flow (Lees and Creed 1977); others linked rise and fall of melanic forms from Britain and America with the increase and decrease of atmospheric pollution (Grant 1999, Grant and Wiseman 2002). Predation has a substantial role in the decline of melanic forms in the post-industrial areas, the melanic moth being selectively eaten by birds given the fact that they are more visible on the trunks of the trees (Cook and Turner 2008, Cook et al. 2012, Cook and Saccheri 2013, van't Hof et al. 2013, van't Hof et al. 2016, Eacock et al. 2017).

\section{Conclusions}

Our data indicate a decline of the carbonaria form in the Copșa Mică area. Used as a bioindicator in the past, this decline suggests that the pollution level is lower now, and the health of the forest habitats has improved. The insularia form, which is independent of the pollution level (Rákosy and Rákosy 1997), is more frequent in 2012. Probably, the carbonaria form will continue to decline in the future and the typica form will become more abundant; additional research is needed to prove this hypothesis.

\section{Aknowledgements}

The authors would like to thank the anonymous referees for improving the preliminary manuscript and for their useful comments. We are grateful to Ilik Saccheri for linguistic corrections and for his constructive comments on the earlier version of this manuscript. Special thanks to Petre Creţu, Nicolae Creţu, Elena Tőrők and Cornel Török for their help during fieldworks. This work was possible with the financial support of the Sectoral Operational Programme for Human Resources Development 20072013, co-financed by the European Social Fund, under the project number POSDRU/107/1.5/S/76841 with the title „Modern Doctoral Studies: Internationalization and Interdisciplinary".

\section{References}

Barbu C.H. (2006) Preliminary study. Screening assessment of the existing data and studies concerning the Copşa Mică industrial area. Proposal of actions to be taken for the accurate determination of the degree of pollution and estimated costs, Lucian Blaga University of Sibiu Publishing House, Sibiu, Romania.

Cook L.M. and Turner J.R.G. (2008) Decline of melanism in two British moths: Spatial, temporal and interspecific variation. Heredity 101: 483-489.

Cook L.M. and Saccheri I.J. (2013) The peppered moth and industrial melanism: evolution of a natural selection case study. Heredity 110: 207-212

Cook L.M., Grant B.S., Saccheri I.J. and Mallet J. (2012) Selective bird predation on the peppered moth: the last experiment of Michael Majerus. Biology Letters 8 (4): 609-612.

Clarke C.A. and Sheppard P.M. (1966) A local survey of 


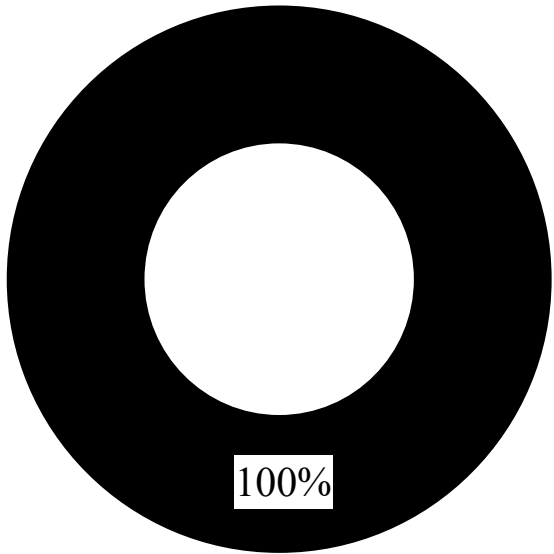

1987

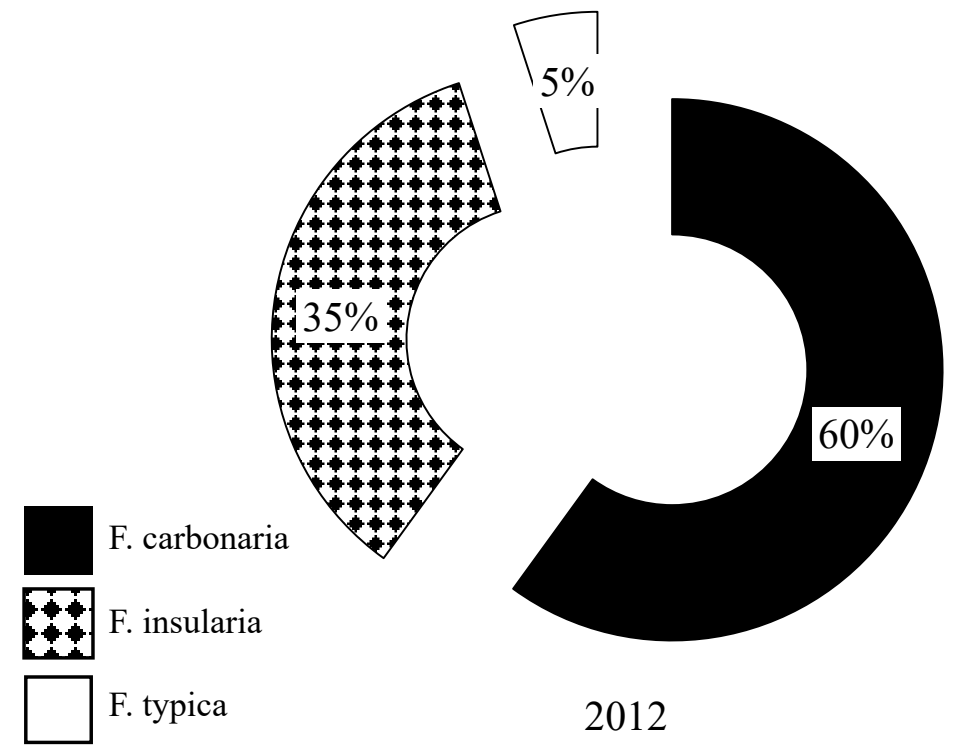

Fig. 2. Frequency of the Biston betularia forms from the medium polluted sites in the year 1987 and 2012

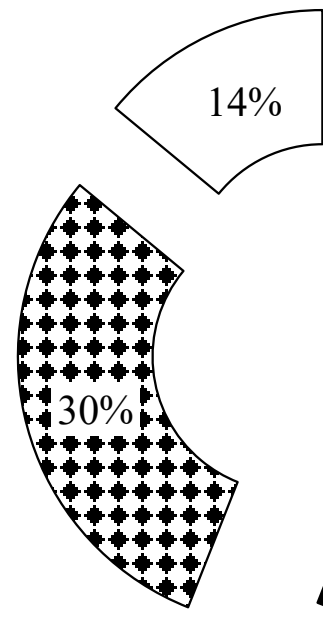

1987

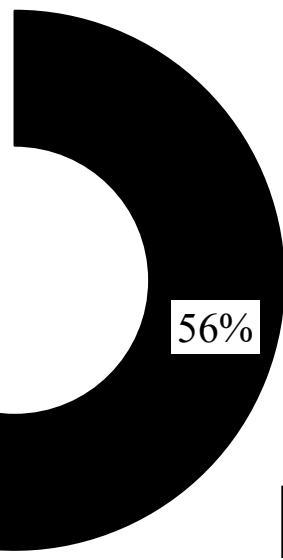

*. F. insularia

F. typica
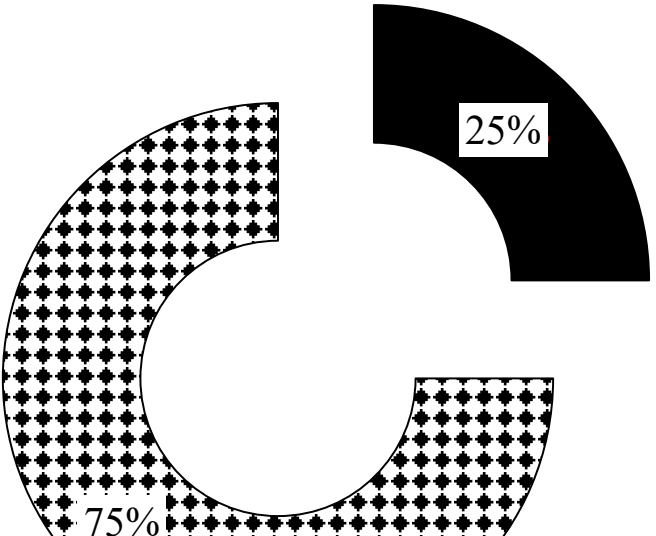

$+75 \%+*+*+*+*+*+*$

$+4+4$

$+\%++\%+\%+$

$++++++$

2012

Fig. 3. Frequency of the Biston betularia forms from the unpolluted sites in the year 1987 and 2012

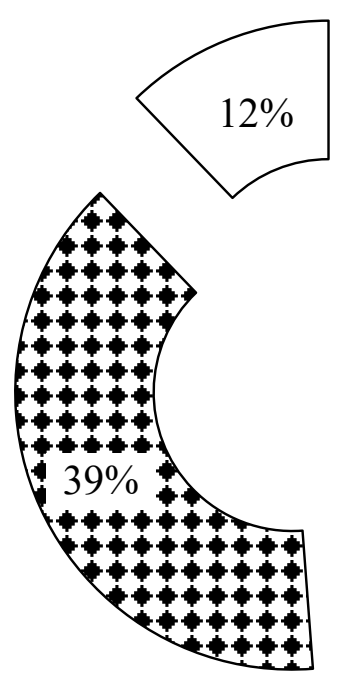

1987

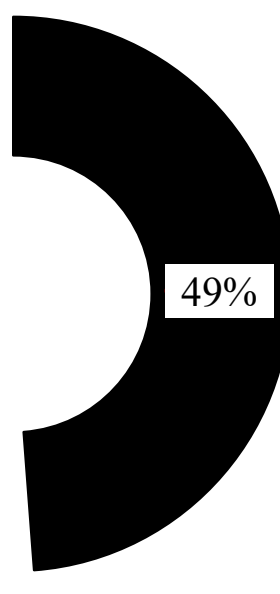

F. $\$$
F. carbonaria

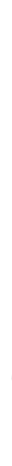

F. typica

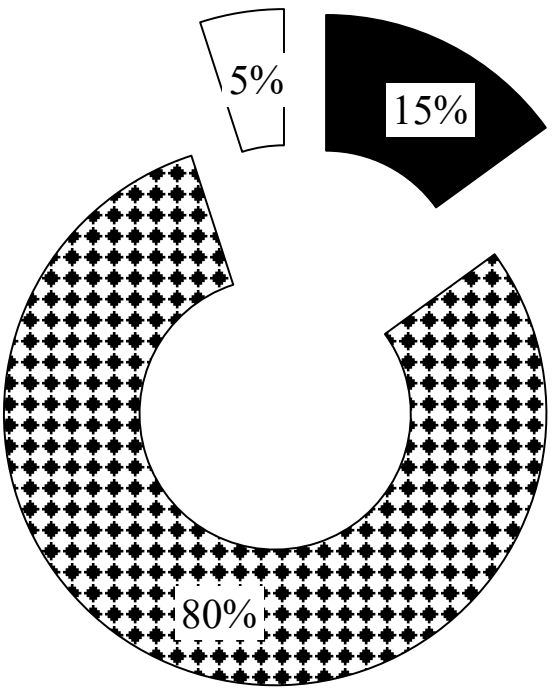

2012 
the distribution of industrial melanic forms in the moth Biston betularia and estimates of the selective values of these in an industrial environment. Proceedings of the Royal Society of London B, 165: 424 - 439.

Eacock A., Rowland H.M., Edmonds N. and Saccheri I.J. (2017) Colour change of twig-mimicking peppered moth larvae is a continuous reaction norm that increases camouflage against avian predators. PEERJ, 5. doi:10.7717/peerj. 3999.

Grant B.S., Cook A.D., Clarke C.A.Y. and Owen D.F. (1998) Geographic and temporal variation in the incidence of melanism in peppered moth populations in America and Britain. Journal of Heredity 89: 465-471.

Grant B.S. and Wiseman L.L. (2002) Recent History of Industrial Melanism in American Peppered Moths. Evolution 53: 980-984.

Kettlewell H.B.D. (1961) Geographical melanism in the Lepidoptera of Shetland. Heredity 16: 393-402.

Lăcătușu R. and Lăcătușu A.R. (2010) Evolution of heavy metals pollution from Copşa Mică. U.A.S.V.M. Bucharest 53 (A): 85-92.

Lees D.R. (1981) Industrial melanism: genetic adaptation of animals to air pollution. In: Bishop J.A. and Cook L.M. (ed.) Genetic Consequences of Man Made Change. Academic Press, London, London.
Rákosy L. and Rákosy L. (1997) Consideraţii asupra melanismului industrial la Biston betularia (Lepidoptera: Geometridae) din zona Copşa Mică. Bul. inf. Soc. lepid. rom. 8(1-2): 57-65

Sanda V., Popescu A., Vasiliu L., Doltu I.M. and Grou E. (1976) Contribuţii noi privind efectele poluării atmosferei asupra florei şi faunei din zona industrială Copşa Mică. Studii şi Comunicări, Ştiinţe Naturale Muzeul Brukenthal Sibiu 15: 113-121.

Szanto M., Micle V. and Prodan C.V. (2011) Study of soil quality in Copșa Mică area with the aim of their remediation. ProEnvironment 4: $251-255$.

Van't Hof A. E., Campagne P., Rigden D. J., Yung C.J., Lingley J., Quail M.A., Hall N., Darby C.A. and Saccheri I.J. (2016) The industrial melanism mutation in British peppered moths is a transposable element. Nature 534(7605): 102-105.

Van't Hof A.E., Nguyen P., Dalíková M., Edmonds N., Marec F. and Saccheri I.J. (2013) Linkage map of the peppered moth, Biston betularia (Lepidoptera, Geometridae): a model of industrial melanism. Heredity 110(3): 283-295.
Sergiu TöRöK

Municipal Museum Mediaș,

Mihai Viteazul 46, Mediaş,

Sibiu, Romania

E-mail: ser.torok@yahoo.com
László RÁKOSY

Department of Taxonomy and Ecology

"Babeș-Bolyai" University,

Clinicilor 5-7, Cluj-Napoca,

Cluj, Romania

E-mail: laszlo.rakosy@ubbcluj.ro
Received: 10.11.2017

Accepted: 30.11.2017

Published online: 28.12.2017

Published: 28.12.2017

Online article number: ER21201701

doi: 10.24193/entomolrom.21.1 